\title{
Analysis and Discussion of Long-Sentence Structure in Legal Translation
}

\author{
Weixuan $\mathrm{Shi}^{1^{*}}$, Dandan $\mathrm{Ma}^{1}$ \\ ${ }^{1}$ School of Foreign Language, North China Electric Power University Baoding, 071000, China
}

DOI: $\underline{10.36348 / \text { sijll.2022.v05i01.005 }}$ | Received: 04.12.2021 | Accepted: 07.01.2022 | Published: 29.01 .2022

*Corresponding author: Weixuan Shi

School of Foreign Language, North China Electric Power University Baoding, 071000, China

\section{Abstract}

This paper analyzes the three elements of the structure of legal English (conditional sentence, logical connector and and or, modified limit components), and proposes how these three elements can be used in Chinese and English legal translation to avoid ambiguity or error in a long sentence.

Keywords: Legal English; long sentence structure; Chinese-English translation.

Copyright $\odot$ 2022 The Author(s): This is an open-access article distributed under the terms of the Creative Commons Attribution 4.0 International License (CC BY-NC 4.0) which permits unrestricted use, distribution, and reproduction in any medium for non-commercial use provided the original author and source are credited.

\section{FOREWORD}

A prominent feature of legal language in written expression is the multiple use of long sentences, which is what the drafters and translators call the structure of the law. This tendency to use long-sentence expression in English, Chinese legal texts is due to the attempt of legislators to place all the relevant information of a certain problem within a complete sentence to avoid possible ambiguities caused by several scattered sentences. The long sentence structure of the legislative language dates back to the period before ancient Rome and Greece, when the long sentence structure of "one sentence" because of no punctuation was widely used in the expression of the legal language, sometimes even using only a long sentence to express the whole content of a certain statute. As society advances, punctuation appears; but laws and regulations have become increasingly complicated. In order to make users easily understand and grasp, a law and regulation is usually divided into several parts to express it, but the expression habit of using a long-sentence structure has been used in the drafting and translation of the law to this day.

\section{CLASSIFICATION AND ANALYSIS OF LONG-SENTENCE STRUCTURE}

\section{Use of a conditional sentence}

Therefore, the use of conditional sentence structure in legal language is very common, due to the normative function of legal language itself and the function of providing information that needs to be realized through prescribed and descriptive means. The heavy use of conditional sentences in sentence expressions attracted attention as early as 1843.George Coode attributes the components of conditional sentences in legal English to: case (case), condition (condition), legal subject (legal subject), and legal action (legal behavior). His more typical analysis is as follows:

- (Case)Where any Quaker refuses to pay any church rates,

- (Condition) if any churchwarden complains thereof,

- (Subject) one of the next Justices of the peace,

- (Action) may summon such Quaker.

Among them, the first two components are used to express the factual situation (fact situation), while the latter two components are used to express the legal subjects and the legal acts they should take.In English legal provisions, factual situations are usually expressed in conditional clauses, while legal statements (statement of law) are expressed through the main sentence.Both constitute a complete statement while expressing a structure of legal logic like "If P1" $+\mathrm{P} 2$, then $\mathrm{Q}$ "1".Thus, the Coode example can be rewritten in the following form:

Fact-situation

Where a churchwarden files A complaint against a Quake For refusing to pay any church rates

Statement of law one of the next Justices of the peace may summon

In the Chinese and English legal translation, it is very necessary for the translator to master the conditional sentence to carry out the translation work 
Weixuan Shi \& Dandan Ma., Sch Int J Linguist Lit, Jan, 2022; 5(1): 38-41

smoothly.Western scholars have properly summarized this characteristic of legal English with the formula:

\section{If $X$, then $Y$ shall do $Z$ \\ If $X$, then $Y$ shall be $Z$}

Here, "If $\mathrm{X}$ " represents the application of the legal system (case), "Y" represents the legal subject (legal subject), and "Z" represents the legal act (legal action).This form of expression is very common in legal English, and is well represented in the following examples.

Example 2: Article 141 (1) Where the subject matter needs to be transported, the seller shall deliver the subject matter to the first carrier to the buyer; ... ...

Article 141 (1) If the targeted matter needs to be transported, the seller shall consign the targeted matter to the first carrier for its delivery to the buyer; ...

Obviously, the understanding of the structure of conditional sentences in legal English helps the translator to be familiar with this kind of expression form of legal English and facilitate the development of the translation work. However, because legal English often uses a long sentence structure, the translator must take the conditional sentence pattern seriously in the translation, so as not to make mistakes in the arrangement and organization of the sentences, which leads to the reversal of the main sentence, for instance:

Example 3: Article 17 an offer may be withdrawn and the notice of withdrawal of the offer shall arrive before the offer arrives at or at the same time with the offer.

Translation: (1): If an offer is recalled, the notice of recall should arrive before the offeree receives the offer or at the same time as the arrival of the offer.

Translation: (2): The offer may be withdrawn, if, before or at the same time when an offer arrives, the withdrawal notice reaches the offeree.

(1) reversed the master clause position, thus reversing the master relationship, which would mistake the reader that "the offer can be withdrawn, but the condition that notice of withdrawal is the time to reach the offeror."(2) corrects the position of the main clause and accurately expresses the primary and secondary relationship and significance of the original text.Therefore, for a legal translation, the translator should note that no matter how long the legal statement (statement of law) is always in the main sentence position, however long or complex a clause is.

\section{Use of the logical connections "and" and "or"}

The logical connections "and" and "or" play an important logical cohesion role in the long sentence structure of legal English, especially when dealing with parallel and parallel or parallel components in a long sentence. In fact, neither the drafters of the law nor the translator of the law should ignore the important role of these logical connectors in promoting the structure of long-sentence expression and realizing accurate logical relations. The and is the conjunctive, while the or is the turning conjunctive. The and is equivalent to "and, and, and" in Chinese, while the or is equivalent to "or" in Chinese. In legal documents, these connectors can determine whether a person commits a crime or defaults on a contract. Some scholars use the following formulas to express the difference of the logical connector and and or in legal English:

(1) If $X$ does $A, B$ and $C, X$ shall be liable to punishment.

\section{(2) If $\mathrm{X}$ does $\mathrm{A}, \mathrm{B}$ or $\mathrm{C}, \mathrm{X}$ shall be liable to punishment.}

In formula (1), $\mathrm{X}$ is only punished if $\mathrm{X}$ performs all three acts, $\mathrm{A}+\mathrm{B}+\mathrm{C}$, but in formula (2), when the turning word or is used, $\mathrm{X}$ implements any of the three acts. From this, we can imagine the serious consequences of translators misuse the logical connector and and or in legal translation.

Example 4: Article 13 If a joint venture enterprise suffers a serious loss, one party fails to perform the obligations stipulated in the contract and the articles of association, and force majeure, the party may terminate the contract through approval to the examination and approval authority and registration with the competent administrative department for industry and commerce.

Article 13 In case of heavy losses, failure of a party to perform its obligations under the contract and the articles of association, or force majeure etc., the parties to the joint venture may terminate the contract through their consultation and agreement, subject to approval by the examination and approval authorities and to registration with the state's competent department in charge of industry and commerce administration.

In the above example, the turning conjunctive or means that only any one of the three conditions can lead to the termination of the contract, and if the or is replaced for and here, the termination of the contract is undoubtedly much increased. Similarly, if the translator replaced the later connector and with or, we will find that the termination of the contract is very different from the original, much more simplified.

To further illustrate the important role of the logical connectors and and or in the long sentence structure, we may look at another example.

Example 5: Article 36 where a contract is concluded in written form if the party fails to take written form but one party has fulfilled the main 
Weixuan Shi \& Dandan Ma., Sch Int J Linguist Lit, Jan, 2022; 5(1): 38-41

obligations and the other party accepts it, the contract shall be established.

Article 36 Where the parties fail to make a contract in written form as provided for by laws or administrative regulations or as agreed by the parties, but a party has already performed the major obligations and the other party has accepted the performance, the contract shall be considered as executed.

In short, we can see from examples 4 and 5 the important logical connection role of the logical connector and and or in the translation of Chinese and English legal translation. The translator must be careful when handling the legal Chinese-English translation; otherwise, negligence may bring serious legal consequences to the users of the translation.

\section{Use of modified restricted components}

Modified qualified components

(qualifications) are important in the long-sentence structure that constitutes legal English. Generally acting as the modification limit component in the sentence expression of legal English are attributive clause, adverbial clause, verb infinitive, participle structure, noun lattice and various prepositional structure. Correct placement of modified qualified ingredients can produce accurate, clear, comprehensive and easy to understand expression effects of legal terms. The next example gives us a better understanding of the function and role of modification limiting components in longsentence structures:

Example 6: Where a secure tenant serves on the landlord a notice in writing claiming to exercise his right to buy the dwelling-house [1], and if the landlord refuses to admit the tenant's right to buy the dwellinghouse [2], then, subject to the following provisions of this Section [3], the Secretary of State, if he thinks proper [4], may by means of a written notification [5] make special regulations in pursuance of his powers under Section 15 of this Act [6] for the purpose of enabling the tenant to exercise his right to buy the dwelling-house [7] (not withstanding anything contained in Section 54 of the Land Registration Act 1925) [8] within a period of six months from the date of such a refusal [9], provided that the dwelling-house, of any part of it, is not being used for charitable purposes [10] within the meaning of the 'Charitable Purpose Act 1954' [11].

In the above example, the underlined part belongs to the modified limiting component of the backbone sentence, totaling 11.Its functions and functions are as follows: (1) (2) (4) (5) (10) preparation conditions (preparatory), indicating specific conditions, conditions, methods, accidents, etc.; (3) (6) (8) (11) has the indicated function (referential), a clear scope and object, and (7) (9) application function (operational), indicating the behavior purpose and time relationship.
Obviously, these modified qualification components are used to clarify the details of the legal provisions, making the various aspects of the main provisions of the law more clear and accurate. Legal language tends to be complicated style and strives to be exhaustive. Whether the translator can properly place the modification qualification component in a sentence partly affects the accuracy of the translation. Of course, for the drafters and translators of legal English, the proper placement of a sentence with different modification of limit components requires more syntactic knowledge. Because, language complexity is increased in an attempt to place all the information in a single sentence.

Example 7: Article 18... The competent foreign economic and trade department under the State Council, together with the relevant departments of the State Council may, within the approval of the State Council prescribed in Article 16 or 17 of this Law, temporarily decide to restrict or prohibit the import or export of specific goods or technologies other than the catalogue specified in the preceding paragraph of the case.

Article $18 \ldots$ The competent department in charge of foreign economic relations and trade under the State Council may, independently or jointly with relevant departments under the State Council, subject to the approval of the State Council and within the scope stipulated in Articles 16 and 17 of this Law, specially decide to restrict or prohibit the import or export of specific goods or technologies which are not included in the catalogue specified in the preceding paragraph.

Obviously, the English translated sentence backbone of example 7 is the competent department may decide to restrict or prohibit the import or export, but we can see the pains that the translator takes to accurately place at least seven complex limiting components.

To solve the problem of how to properly place multiple modification limiting components in the same sentence, most drafters and translators of legal English tend to keep the modified restricted components as closely as possible, although sometimes losing the beauty and continuity of the sentence, accurate expression, and otherwise, sentence structure and expression do not necessarily achieve accurate expression, and may even lead to ambiguity or error in the translation.

Example 8: Article 48 A contracts made in the name of the principal without the agent or the termination of the agent shall have no effect on the principal without his chase recognition, and the actor shall bear the responsibility. 
Original Article 48 a contract concluded by an actor who has no power of agency, who oversteps the power of agency, or whose power of agency has expired and yet concludes it on behalf of the principal, shall have no legally binding force on the principal without ratification by the principal, and the actor shall be held liable.

Translation: Article 48 A contract in the name of a principal and without ratification by the principal, and yet actually concluded by an actor who has no right of agency or oversteps the right of agency, or whose right of agency has expired, shall have no binding force on the principal; and the actor shall be held liable therefore.

First, the syntax error exists in the original translation, and the subject of the yet concludes it sentence is unknown; moreover, the modification limit component of the translation central word A contract is only listed randomly following the original text, which is not clear enough, and the translator does not carefully deliberate, which can easily confuse the recipient of the translation. The translation avoids the grammar error, and also properly places the modification limit components, so that the translation logical relationship is clear, accurate meaning expression and easy to understand.

Therefore, the translator in a long sentence should remember: as a general principle, each modification limit component should be placed in "as close as possible to the modified component in the sentence, so that it will appear 'logical with the connection of the modified component and natural' ".

\section{SUMMARY}

In the practice of Chinese and English legal translation, some translators will try to follow the sentence structure of the original text, lest that any small change may cause translation errors; especially when translating longer sentences, more people feel less confidence. However, legal translators should realize that legal translation is another innovation process, and it is a positive and restricted innovation process limited by the framework of law, language, culture and other factors. Therefore, when understanding the characteristics of the long sentence structure of legal English and its constituent elements, the translator can correctly and creatively deal with the Chinese-English translation problems in legal documents: correcting the principal relationship of conditional sentences, the rational use of logical connections and and or, and properly placing multiple modified qualification components in a long sentence. In this way, we will have more confidence and less concern when dealing with the translation of such long sentences in the Chinese and English legal translation.

\section{REFERENCE}

1. Sarcevic, S. (1997). New Approach to Legal Translation [M]. (P.130-131); (P.136); (P.136); (P.164); (P.151); (P.165)The Hague: Kluwer Law International.

2. Zhang, X. (2001). Text Types and Legal Text [J]. Modern Foreign Language, (2); 198.

3. Gibbons, J. (1994). Language and the Law [M].(P.150); (P.154);(P.7) New York:Longman Publishing.

4. Weiliang, F. U. (2002). Translation of the Contract Legal Documents [J].Chinese Translation, 5; 45.

5. Law of the People's Republic of China on SinoForeign Joint ventures (Chinese and English comparison) [M]. (2001). Beijing: China Legal Press, 38-39.

6. Qin, X. (1997). Introduction to Style [M].Changsha: Hunan Education Publishing House, page 285.

7. Foreign Trade Law of the People's Republic of China. (2001). (Chinese and English comparison) [M].Beijing: China Legal Press, 12-13.

8. Contract Law of the People's Republic of China. (2002). (Chinese and English comparison) [M].Beijing: China Legal Press House, 22-25.

9. Dukin, list. (2004). Legal linguistics [M]. Shanghai: Shanghai Foreign Language Education Press, 159. 